\title{
小学数学课堂教学中小组合作学习的运用策略研究
}

于泽凡

内蒙古赤峰市喀喇沁旗锦山第二小学

DOI:10.32629/jief.v2i6.1060

[摘 要] 随着新课程改革的推进, 学校越来越重视对学生综合素质的培养。数学作为三大主要学科之一, 在学生的学习生涯中占有很大的比 重, 而小学数学作为整个数学学习的基础, 更是要引起大家的重视。在此背景下, 教师将合作学习的教学模式引入了小学数学课堂, 在激起 学生学习兴趣的同时, 还可以培养其合作意识和集体荣誉感。本文深入探讨了合作学习模式中存在的问题并对其提出了一些建议。

[关键词] 小学数学; 课堂教学; 合作学习; 运用策略

中图分类号：G633.6 文献标识码：A

随着时代的进步, 人们逐渐发现了合作的重要性, 合作精神在教学 中也可以发挥其作用。合作学习打破了以往的教学模式, 学生可以参与 到学习中去, 与教师和同学平等的交流、讨论, 这可以提升学生的数学 素养, 也可以加强其语言逻辑和理解能力。小组合作学习的模式弱化了 个人的成就感, 更加突出团队的成绩, 这就激起了学生的集体荣誉感。 因此, 将小组合作学习引入到小学数学的课堂教学中, 不仅可以锻炼学 生的各方面能力, 更有利于数学教学的开展, 增强教学成果。

\section{1 在数学教学中开展合作学习的缺陷分析}

\section{1 小组成员分配不均衡}

由于教师对学生的实际情况不了解, 可能导致各个小组成员的综合 实力不对等。有的小组普遍学习能力较强, 基础较好, 就有可能在讨论 时各执已见, 不听取他人的意见, 也不能发挥一些同学的个人优势和实 力。而有的小组可能没有足够能力能领导起这个小组的成员, 导致该小 组比较散乱, 实现不了合作学习。

\section{2 将小组合作学习 “形式化”}

由于教师对合作学习的理解不够深刻和全面, 导致其趋于 “形式化” 和 “表面化”, 并没有真正做到合作学习。有些教师并不改变以往的教学 模式, 只是将学生进行简单的划分, 小组之间并没有分享和讨论, 也就 没办法实现真正意义上的合作学习。还有些教师认为所有的课堂教学都 可以通过合作学习来实现, 并不考虑课堂内容的可操作性和学生的自身 情况, 使合作学习失去了其教学意义, 反而影响了课堂效率和学生的学 习效果。

\section{3 学生参与的积极性不高}

素质教育要求以学生为中心, 合作学习模式充分体现了这一点, 作为 合作学习的核心，学生应该积极参与到合作与讨论中去。而合作学习中常 见的问题就是学生参与的兴致不高, 由于学生的集体意识不高, 合作意识 不强, 导致其不积极的发表自身对于问题的看法, 不与小组其他成员交流、 讨论。如果只有一两个同学发表意见, 分析、讨论问题, 那合作学习的教 学模式也就无法顺利开展, 也就失去了开展合作学习的意义。

\section{2 将合作学习运用到数学教学中的建议}

\section{1 科学安排小组成员}

教师在教学中处于主导地位, 在设计教学活动时要注意活动的可实 施性和教学效果。在开展合作学习时应该先规划好小组成员的人数, 人 数过多学生可能借机聊天; 人数过少可能组内讨论达不到很好的效果, 而且组别过多也不易于管理。同时在分配小组成员时要以学生自身的实
际情况为依据, 保证每个小组都有学习能力强的, 可以带领组内其他基 础相对较差的学生一起讨论。在合作学习的课堂上, 要保证学习小组的 科学、合理分配, 才能使学生之间相互学习, 共同提高, 进而实现更高 的教学目标。

2.2 选取合适的教学内容

合作学习并不适用于全部教学内容, 所以选取恰当的教学内容就会 直接影响着教学效率和学生的学习效果。教师作为学生学习路上的引导 者, 要在选题目时格外用心, 既不能太简单, 学生不用多加思考就能想 出答案的; 又不能太难, 讨论好久都没有头绪, 整理不清思路。要让学 生通过对该问题的讨论对知识点了解的更加全面, 记忆更加深刻。最好 是开放性的题目, 让学生既能学到知识, 又能拓展思维。

2.3 建立奖励机制设立竞争环节

小组内成员在合作学习中互相帮助, 共同提高, 是合作关系; 但在 小组间就产生了竞争关系。教师可以设立竞争环节和积分奖励制度, 以 此来引起学生学习的兴趣和积极性。而学生为了给小组争得荣誉, 会在 合作中更加积极、认真, 拿出一百二十分的努力来对待教师提出的问题。 这种方法既能使学生更好的掌握知识, 又能增强其集体荣誉感, 更能激 发其内在的潜能, 对于教学效率和个人能力来说都是有所提高的。

\section{3 总结}

综上所述, 在小学数学教学中引入小组合作学习的模式对于提高学 生的学习效率和综合能力都有着显著成效, 更是对数学教学的开展有着 积极的推进作用。学生通过小组合作学习, 不仅学到了知识, 还能深刻 的理解合作的意义和重要性, 对其未来的学习和生活都有着很大的积极 影响。培养学生的合作意识不仅可以帮助其更好更深入了理解数学知识, 更有利于其今后在更多的方面通过与他人合作获得更高的成就。在合作 学习中, 学生通过小组成员间的分享与讨论, 和教师的平等交流等, 改 善了学生与教师间的关系, 使课堂氛围更和谐、更活跃, 进而提高课堂 效率, 增强教学成果。

\section{[参考文献]}

[1]隋洪星.小组合作学习模式在小学数学课堂教学中的应用 [J]. 学 周刊,2016(30):70-71.

[2] 郭淑红. 小学数学课堂教学中小组合作学习的运用策略分析 [J]. 中国校外教育,2015(06):127。

[3]吴艳春.小组合作学习在小学数学教学中的运用策略 [J].中国科 教创新导刊,2013(13):47. 